\author{
Humanities and Social Sciences Letters \\ 2022 Vol. 10, No. 1, pp. 27-35. \\ $\operatorname{ISSN}(e): 2312-4318$ \\ $\operatorname{ISSN}(p): 2312-5659$ \\ DOI: $10.18488 / 73 . v 10 i 1.2229$ \\ (C) 2022 Conscientia Beam. All Rights Reserved. \\ check for
updates
}

\title{
PATTERNS OF SOCIAL MEDIA USAGE AMONG MALAYSIANS DURING THE COVID- 19 PANDEMIC
}

(D) Aisah Meri ${ }^{1+}$
(iD Syahruddin Awang
Ahmad $^{2}$
(D) Sitinurbayu Mohd
Yusoff $^{3}$
(iD Noor Syakirah
Zakaria $^{4}$
(iD Fauzie Sarjono
(D) Amrullah
Maraining
(iD Zainuddin Baco $^{7}$

Article History

Received: 7 October 2021 Revised: 26 November 2021 Accepted: 20 December 2021 Published: 4 January 2022

\section{Keywords}

Needs

Uses

Gratifications

Social media

Audiences

Covid-19.

\author{
${ }_{1,2,3,4,5,6,7}$ Faculty of Social Sciences and Humanities, University of Malaysia \\ Sabah, Malaysia. \\ 'Email:aisah.meri@ums.edu.my Tel:6013-8647928 \\ 'Email:syahag@ums.edu.my Tel:6012-8697486 \\ ${ }^{s}$ Email: bayu.yusoff@ums.edu.my Tel: 6012-7166961 \\ "Email:syakirah@ums.edu.my Tel: 6013-8993479 \\ ${ }^{5}$ Email: fauzie@ums.edu.my Tel: 6016-7737998 \\ ${ }^{6}$ Email: amrullahmaraining86@ums.edu.my Tel: 6014-6549568 \\ ${ }^{7}$ Email: zainuddin@ums.edu.my Tel: 6019-8038995
}

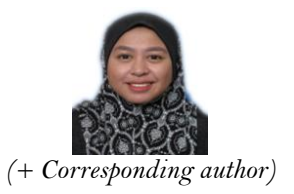

ABSTRACT

This paper explores the use of social media among Malaysians during the Covid-19 pandemic. Questionnaires were distributed to 424 people in Malaysia who were directly affected by the Covid-19 pandemic. The research findings revealed that the main reasons that drove people to use social media were cognitive aspects, escapism, affective factors, and social integration. The data also shows that Malaysians frequently employed social media to search for information, for diversion purposes, and due to habit. Meanwhile, the highest levels of gratifications were derived from factors of convenience, surveillance, and interpersonal discussion. This study concludes that social media plays a crucial role for Malaysians while confronting the Covid-19 pandemic, alongside other media components. It cannot be denied that technology also influenced uses and gratifications among the audiences. The uniqueness of social media, coupled with the smartphone, gives it a distinct advantage over other media forms. The audiences had at their disposal a multitude of information that could bring numerous usages and forms of gratifications.

Contribution/Originality: This study investigated the patterns of social media usage among Malaysians based on uses and gratifications $(\mathrm{U} \& \mathrm{G})$ theory. The study examined three main variables in this theory (needs, uses and gratifications) to understand social media usage patterns during Covid-19 pandemic which is interesting to explore.

\section{INTRODUCTION}

In December 2019, the world was shocked by the Covid-19 pandemic, which originated from the SARS-CoV2 virus that had the ability to cripple the human respiratory system and, in serious cases, be fatal (Zhu et al., 2020). The spread of Covid-19 to Malaysia was detected on January 24, 2020, amongst travelers who had returned to Malaysia after visiting countries that had been infected earlier (World Health Organization, 2020). The rapidly increasing infection rate in Malaysian society led to the government imposing the Movement Control Order (MCO) 
on March 18, 2020 (Kaur, 2020). This measure was taken for the purpose of breaking the chain of Covid-19 infection, which was rising alarmingly among Malaysians (Yassin, 2020).

Unlike earlier times, when the masses could only rely on conventional media to obtain information whenever a crisis occurred, now they have a host of options to source information, and this is mainly due to the development of technology involving the internet and information and communication technology (ICT). The rapid expansion of the mediascape through technology, such as the internet and social media, is seen as being critical for information delivery, especially when the world is facing a crisis such as the Covid-19 pandemic. Hence, the question that calls for our attention is: How has the media usage changed among Malaysians during the Covid-19 situation? The Malaysian Communications and Multimedia Commission (MCMC) reported that internet usage had surged dramatically among Malaysians during the Covid-19 pandemic in 2020.

The rate of social media usage in Malaysia, for instance, showed a 93\% increase, with Malaysians averaging between five and 12 hours daily of internet usage (Malaysian Communications and Multimedia Commission, 2020). This clearly illustrates that social media usage among audiences in Malaysia facing the pandemic had become markedly more active. This research intends to study the usage activity of social media among the audiences in Malaysia in greater detail by employing the uses and gratification (U\&G) theory as the primary research framework.

\section{OBJECTIVE}

The objectives of this research are to:

i. Identify the needs that encourage Malaysian audiences to use social media during the Covid-19 pandemic.

ii. Identify the forms of social media used among Malaysian audiences during the Covid-19 pandemic.

iii. Identify the forms of social media gratifications among Malaysian audiences during the Covid-19 pandemic.

\section{HIGHLIGHTS OF PREVIOUS STUDIES}

Media utilization studies among audiences often employ the uses and gratification (U\&G) theory to give actual depictions of media usage patterns (Rubin, 2009). Besides the assumption that audiences are actively engaged in media usage, this theory also posits that audiences make use of the same media to fulfil different needs, uses and gratifications (Katz, Gurevitch, \& Haas, 1973; Lee, Nayan, \& Othman, 2016; Meri, Lee, Yusoff, \& Modili, 2020; Ruggiero, 2000). Concurrent with new mediascape developments, this theory is frequently used to view conventional media usage as well as new media (Ruggiero, 2000). Past studies have placed much emphasis on the specific needs that encourage audiences to use media. Katz et al. (1973), for example, have postulated that the same needs can be observed among audiences with regards to media usage, and that all these needs can be grouped into five types, namely cognitive needs, affective needs, self-integration needs, social integration needs, and escapism needs. It is also noted that audiences frequently use conventional media as well as the latest media to fulfil their cognitive and affective needs (Akmar \& Siti, 2015; López, Hartmann, \& Apaolaza, 2019).

Past studies that have applied the use and gratification perspective have succeeded in creating various motive typologies regarding usage of conventional media and new media (Ambika \& Samy, 2018; Cortese \& Rubin, 2010; Foregger, 2009; Kircaburun, Alhabash, Tosuntaş, \& Griffiths, 2020; Ku, Chu, \& Tseng, 2013). The use and gratification perspective has also frequently been applied as a theoretical framework for looking at social media usage among audiences whenever a crisis happens (Aisha, Wok, Manaf, \& Ismail, 2015; Maxwel, 2012; Wang, 2021). For instance, social media is regularly used as one of the platforms to seek and share information when crises such as natural disasters take place (Liu, Fraustino, \& Jin, 2015). Meanwhile, looking at social media usage during the pandemic crisis, it was found that social media usage among audiences in Malaysia has seen a drastic increase compared to the previous year (MCMC, 2020). Audiences were also keen to read news reports, utilizing social media for purposes of locating information of current issues happening around them (Lin, Hsu, Chen, \& Fang, 2017; 
Nayan, Devarajoo, Othman, Lee, \& Hasan, 2016). This clearly shows that news reports are very much needed in times of crisis.

Earlier research also found that the motive of searching for information was the most obvious in the usage of new media, especially online current news (Akanda \& Haque, 2013; Mathew, Ogedede, \& Adenji, 2013; Michailina, Andreas, \& Christos, 2015; Shim, You, Lee, \& Go, 2015). This trend continued in the wake of the Covid-19 crisis, where audiences keenly resorted to traditional media, social media and online sources to search for information, even though there was a high frequency of fake news circulating among the masses (Apuke \& Omar, 2021; Lachlan, Hutter, Gilbert, \& Spence, 2021). According to Ismail, Ariffin, \& Abdullah (2020), the Movement Control Order $(\mathrm{MCO})$ in Malaysia resulted in the upsurge of social media usage as audiences very much needed information regarding the pandemic.

\section{METHODOLOGY}

This article resulted from a quantitative study involving a survey of 424 respondents from a number of states in Malaysia, namely Sabah, Sarawak, Selangor, Johor, Pulau Pinang, Kelantan, Negeri Sembilan, Terengganu and Pahang. This method was chosen based on viable, valid reasons; indeed, Wimmer \& Diminick (1994) in many of their works pertaining to studies on use and gratification depended on the survey method. This assertion can also be verified from earlier scholars who employed the survey method to conduct research on levels of use and gratification of a particular media (Alhabash \& Ma, 2017; Wang, 2021; Wu, Wang, \& Tsai, 2010). Also, this method was selected based on the research objective, that is to test social media use and gratification behavior of audiences in Malaysia when confronted with the Covid-19 pandemic. The study was done using purposive sampling, whereby only the portion of audiences that used social media was selected to observe their social media usage patterns. All items tested in this research showed a high level of reliability, with all measured items recording Cronbach's alpha readings of 0.90 and above.

\section{RESEARCH FINDINGS}

The results of the research findings are presented in three sections based on the three main objectives. First, the demographics of the respondents are presented.

Table 1. Demography of respondents.

\begin{tabular}{l|c}
\hline Demographic Factors & Percentage Statistics \\
\hline Ethnicity & 69.1 \\
\hline Bumiputera (Sabah) & 10.7 \\
\hline Bumiputera (Sarawak) & 16 \\
\hline Malay & 2.1 \\
\hline Chinese & 2.1 \\
\hline Indian & \\
\hline Gender & 40 \\
\hline Male & 60 \\
\hline Female & 28.3 \\
\hline Age & 9.9 \\
\hline 17 to 22 years & 30.4 \\
\hline 23 to 28 years & 16 \\
\hline 29 to 34 years & 15.3 \\
\hline 35 to 49 years & \\
\hline 49 years and above & \\
\hline Note: N=424. &
\end{tabular}

Overall, a total of 424 respondents were involved in this study, and the process of distributing questionnaires started on June 10, 2021, and ended on June 25, 2021. As can be seen in Table 1 above, the majority of respondents were Bumiputera from Sabah (69.1\%), followed by Malays (16\%), while Bumiputera from Sarawak made up $10.7 \%$. 
Chinese and Indian respondents were in equal numbers (2.1\%). In this study, females were the majority (60\%) outnumbering the males, who made up 40\% of respondents. In terms of age, the majority of respondents were aged between 29 and 34 years of age (30.4\%), followed by respondents in the 17 to 22 age category (28.3\%), while those in the 41 to 49 age category comprised $16 \%$. Finally, respondents in the category of 49 years and above, and those in the 23 to 28 years category, registered $15.3 \%$ and $9.9 \%$, respectively.

Table 2. Average duration of daily social media usage.

\begin{tabular}{l|c|c}
\hline Average Time & Frequency $(\boldsymbol{f})$ & Percentage $(\%)$ \\
\hline Less than 1 hour & 13 & 3.1 \\
\hline 1 to 2 hours & 70 & 16.5 \\
\hline 3 to 4 hours & 98 & 23.1 \\
\hline More than 4 hours & 243 & 57.3 \\
\hline Note: $\mathrm{N}=424$.
\end{tabular}

Table 2 above depicts the average daily usage time for social media among audiences in Malaysia when facing the Covid-19 pandemic. Most respondents (243; 57.3\%) spent more than four hours on social media daily. This was followed by those who spent three to four hours daily (98; $23.1 \%)$, while 70 respondents (16.5\%) spent between one and two hours on social media daily. Finally, 13 respondents (3.1\%) spent less than one hour daily on social media. This clearly indicates that social media usage among Malaysians is high.

Table 3. Social media usage during the pandemic.

\begin{tabular}{l|c|c}
\hline Media & $\mathbf{M}$ & SD \\
& $\boldsymbol{\mu}$ & $\boldsymbol{\sigma}$ \\
\hline Facebook & 3.69 & 1.234 \\
\hline Instagram & 3.20 & 1.411 \\
\hline Twitter & 2.10 & 1.416 \\
\hline WhatsApp & 4.64 & 0.703 \\
\hline YouTube & 3.86 & 1.063 \\
\hline Note: $\mathrm{N}=424$.
\end{tabular}

The first question posed in this study is regarding the type of social media that was given priority among Malaysians when facing the Covid-19 pandemic. Table 3 above presents the main social media usages among Malaysians. Findings reveal that WhatsApp is the most popular social media $(\mu=4.64, \sigma=.70)$, followed by YouTube $(\mu=3.86, \sigma=1.06)$, Facebook $(\mu=3.69, \sigma=1.23)$ and Instagram $(\mu=3.20, \sigma=1.41)$. However, Twitter received less attention, registering the lowest mean levels $(\mu=2.10, \sigma=1.41)$.

Table 4. Most popular gadgets during pandemic

\begin{tabular}{l|c|c}
\hline Media & $\mathbf{M}$ & SD \\
& $\boldsymbol{\mu}$ & $\boldsymbol{\sigma}$ \\
\hline Smartphone & 4.57 & 0.777 \\
\hline Laptop & 2.67 & 1.410 \\
\hline Tablet & 1.72 & 1.220 \\
\hline Note: $\mathrm{N}=424$.
\end{tabular}

Table 4 above illustrates the main gadgets used to access social media among respondents. Smartphones had the highest usage $(\mu=4.57, \sigma=0.77)$, next came laptops $(\mu=2.67, \sigma=1.41)$, while tablets had the lowest usage $(\mu=$ $1.72, \sigma=1.22)$.

To understand the needs that encourage social media usage among the respondents, there are some variable items that they were asked, and this was followed by sub-items for each of the main variables. Table 5 above shows the needs that encouraged social media usage among audiences when confronted by Covid-19 in Malaysia. Generally, this study found that the main needs that encouraged social media usage among Malaysians were 
cognitive needs $(\mu=4.46, \sigma=.61)$, followed by escapism needs $(\mu=4.39, \sigma=.74)$, and affective needs $(\mu=4.25, \sigma=$ $.75)$.

Table 5. Needs for social media usage during the Covid-19 pandemic

\begin{tabular}{|c|c|c|}
\hline Needs for Social Media Usage & $\begin{array}{l}M \\
\mu\end{array}$ & $\begin{array}{c}S D \\
\sigma\end{array}$ \\
\hline Cognitive & 4.46 & 0.618 \\
\hline Need to keep up with current developments about Covid-19 & 4.61 & 0.635 \\
\hline Need to know what others are saying about Covid-19 issues & 4.36 & 0.840 \\
\hline Need to know how others are living and thinking when facing Covid-19 issues & 4.32 & 0.843 \\
\hline Need to know information regarding Covid-19 within and outside the country & 4.54 & 0.676 \\
\hline Affective & 4.25 & 0.753 \\
\hline Need to be constantly entertained during the Movement Control Order (MCO) & 4.08 & 1.027 \\
\hline Need to always feel calm during the Movement Control Order (MCO) & 4.51 & 0.798 \\
\hline $\begin{array}{l}\text { Need to obtain pleasure by using social media during the Movement Control Order } \\
(\mathrm{MCO})\end{array}$ & 4.17 & 0.977 \\
\hline Escapism & 4.39 & 0.747 \\
\hline Need to avoid boredom during the Movement Control Order (MCO) & 4.44 & 0.817 \\
\hline Need to avoid feeling lonely during the Movement Control Order (MCO) & 4.27 & 0.978 \\
\hline Need to release stress during the Movement Control Order (MCO) & 4.46 & 0.774 \\
\hline Social Integrative & 3.82 & 0.877 \\
\hline Covid-19 issues need to become the main topics of discussion with friends and family & 3.88 & 0.947 \\
\hline Need to exchange views with friends via social media & 3.97 & 1.009 \\
\hline Need to seek out friends to discuss issues related to Covid-19 & 3.61 & 1.093 \\
\hline
\end{tabular}

Social integrative needs were not seen as principal needs encouraging audiences to use social media $(\mu=3.82, \sigma$ $=.63)$. Cognitive needs were translated by people as the need to gain knowledge about the Covid-19 issues that were prevalent in their environment. The sub-item of needing to know what others were saying regarding Covid19 issues $(\mu=4.61, \sigma=.77$ ), as well as needing to obtain news about Covid-19 that was taking place both within and outside the country $(\mu=4.54, \sigma=.67)$ were the most critical for people when using social media. Social media was used as one of the means for escapism whereby they needed to destress when the Movement Control Order (MCO) was imposed $(\mu=4.46, \sigma=.77)$, and also to avoid feelings of boredom during the MCO $(\mu=4.44, \sigma=.81)$. For affective needs, social media usage during the MCO enabled individuals to gain peace of mind $(\mu=4.51, \sigma=$ $.79)$; it was also able to provide pleasure $(\mu=4.17, \sigma=.97)$.

Table 6. Social media usage factors during the Covid-19 pandemic.

\begin{tabular}{|c|c|c|}
\hline Social Media Usage Factors & $\begin{array}{l}M \\
\mu\end{array}$ & $\begin{array}{l}S D \\
\sigma\end{array}$ \\
\hline Searching for Information & 4.34 & 0.758 \\
\hline Searching for information on the total number of Covid-19 infections & 4.23 & 0.909 \\
\hline Searching for information regarding vaccines for Covid-19 & 4.18 & 0.905 \\
\hline Searching for information regarding incentives or financial aid from the government & 4.07 & 0.998 \\
\hline Increasing knowledge regarding Covid-19 issues & 4.39 & 0.776 \\
\hline Using social media to search for reliable information regarding Covid-19 & 4.43 & 0.775 \\
\hline Habit & 4.26 & 0.704 \\
\hline Using social media is compulsory for me every day & 4.28 & 0.900 \\
\hline It has become routine to use social media during the Covid-19 outbreak & 4.40 & 0.778 \\
\hline Using social media is my leisure activity during the Movement Control Order (MCO) & 4.33 & 0.850 \\
\hline Diversion & 4.30 & 0.807 \\
\hline Using social media to reduce stress during the Movement Control Order (MCO) & 4.35 & 0.855 \\
\hline Using social media to avoid boredom during the Movement Control Order (MCO) & 4.38 & 0.825 \\
\hline Using social media to give me peace during the Movement Control Order (MCO) & 4.16 & 0.954 \\
\hline
\end{tabular}

Note: $\mathrm{N}=424$. 
Social integration is viewed as the need to communicate with other people, and it is not a principal need that encouraged social media usage, compared to other major needs. The social integration sub-item denoted that the need to exchange opinions on social media was the main need $(\mu=3.97, \sigma=1.00)$, along with the need to make the issue of Covid-19 the topic of primary discussion with friends and family $(\mu=3.88, \sigma=.94)$.

Table 6 above presents the social media usage among Malaysians when facing the Covid-19 pandemic. Results from the analysis discovered that of the three factors under social media usage, the factor of information searching was the dominant factor $(\mu=4.34, \sigma=.75)$; this was followed by the diversion factor $(\mu=4.30, \sigma=.80)$, and then the factor of usage due to habit $(\mu=4.26, \sigma=.70)$. The factor of information searching was the most critical, in which social media was used to find trustworthy information regarding Covid-19 $(\mu=4.43, \sigma=.77)$, followed by increasing knowledge regarding the pandemic $(\mu=4.39, \sigma=.77)$, and then using social media to gather information about Covid-19 infection statistics $(\mu=4.23, \sigma=.90$. The factor of diversion was listed as the second biggest usage of social media, and this can be translated as a means of avoiding boredom during the MCO period $(\mu=4.38, \sigma=$ $.82)$, reducing stress during the MCO period $(\mu=4.35, \sigma=.85)$, and finally to gain peace of mind during the MCO period $(\mu=4.16, \sigma=.95)$. For the factor of habitual use, audiences looked upon social media as a routine, especially during the Covid-19 pandemic $(\mu=4.40, \sigma=.77)$, and as a leisure activity during the Covid-19 pandemic and MCO period $(\mu=4.33, \sigma=.85)$.

Table 7. Social media gratifications during pandemic

\begin{tabular}{l|l|l}
\hline Social Media Gratifications & $\boldsymbol{M} \boldsymbol{S D} \boldsymbol{\sigma}$ \\
\hline Convenience & 4.46 & 0.688 \\
\hline Convenient to obtain information about Covid-19 issues at any time & 4.51 & 0.711 \\
\hline Convenient to obtain information about Covid-19 issues quickly & 4.53 & 0.703 \\
\hline Convenient to share information quickly & 4.43 & 0.813 \\
\hline Convenient to share links to information about Covid-19 on social media & 4.36 & 0.88 \\
\hline Interpersonal Discussion & 4.18 & 0.810 \\
\hline Discuss new information regarding Covid-19 issues with family and friends & 4.18 & 0.872 \\
\hline Share experiences and knowledge about Covid-19 issues with friends and family members & 4.20 & 0.874 \\
\hline Discuss any Covid-19 issue & 4.16 & 0.897 \\
\hline Surveillance & 4.25 & 0.734 \\
\hline Always be connected with the outer environment & 4.12 & 0.903 \\
\hline Directly find out about Covid-19 issues within and outside the country & 4.30 & 0.820 \\
\hline Monitor Covid-19 issues more closely & 4.24 & 0.836 \\
\hline Fulfil the desire to be informed and to be constantly updated about Covid-19 issues & 4.33 & 0.814 \\
\hline Note: N $=424$ & &
\end{tabular}

Table 7 above presents the social media gratifications during the Covid-19 pandemic in Malaysia. Analysis of the results regarding social media gratifications when confronting the Covid-19 pandemic revealed that the convenience aspect of social media was the biggest form of gratification among audiences $(\mu=4.46, \sigma=.68)$. This was followed by the gratification of monitoring $(\mu=4.25, \sigma=.73)$, and then the gratification of interpersonal discussion $(\mu=4.18, \sigma=.81)$. With regard to social media gratifications that were considered convenient, this was translated to the ease of finding out about Covid-19 issues quickly ( $\mu=4.53, \sigma=.70$ ), easy to obtain information about Covid-19 at any time through social media $(\mu=4.51, \sigma=.71)$, convenience of sharing information quickly $(\mu$ $=4.43, \sigma=.81)$, and also convenient to share links about Covid-19 through social media $(\mu=4.36, \sigma=.88)$. Meanwhile, people in Malaysia translated the gratifications of surveillance in social media usage as gratifications achieved by fulfiling their desire to be informed and be constantly updated regarding Covid-19 issues $(\mu=4.33, \sigma=$ $.81)$, directly finding out about Covid-19 issues occuring both within and outside the country $(\mu=4.30, \sigma=.82)$, monitoring Covid-19 issues more closely $(\mu=4.24, \sigma=.83)$ and also the satisfaction of being constantly in touch with the environment around them $(\mu=4.12, \sigma=.90)$. 


\section{DISCUSSION}

The audiences, social media, and technological facilities cannot be viewed separately when confronted by a crisis (Aisha et al., 2015). This study concludes that social media usage among audiences in Malaysia when facing the Covid-19 pandemic was at an active level. This finding is in accord with a report released by the Malaysian Communications and Multimedia Commission (2020), where it was seen that the pattern of social media usage among Malaysian society was found to be very high when the Covid-19 crisis occurred. Most of the audiences stated that their social media activity exceeded four hours daily. WhatsApp was the most frequently utilized social media application during the Covid-19 pandemic, and this was followed by Facebook, YouTube, Instagram and Twitter, in that order. Research findings corroborate that the factor of determination technology through social media greatly influenced usage among audiences during the pandemic. The determination technology factor was regularly discussed by earlier scholars in efforts to comprehend the usage of new media (Lee et al., 2016; Meri \& Lee, 2021). Research findings also uncovered that smartphone usage among Malaysian society registered the highest compared to other devices such as laptops and tablets.

It cannot be denied that socio-psychological needs are interrelated with the choice of media, which then also influences media usage of the individual, and this can be witnessed through social media usage with the onset of the pandemic (Wang, 2021). The discovery of cognitive needs as the most critical needs regarding social media usage highlights that audiences in Malaysia are extremely cognizant of the need for information and awareness of their environment, especially when confronted by this pandemic. This was made clear by the responses obtained in this study, where the audiences needed Covid-19-related information to reduce stress and alleviate their worries. This is very much in accordance with the main factor of usage, namely information searching. WhatsApp and Facebook were the social media platforms that were most frequently utilized for searching for and sharing information relating to Covid-19, for instance, the number of infections, vaccines, and aid from the government. Furthermore, the main gratifications obtained by Malaysian audiences were easy access and easy sharing of information in a rapid manner. The concept of easy accessibility reflects the studies undertaken by Nayan et al. (2016) and Meri et al. (2020), in which they referred to the convenience of smartphones which are easy for people to access, carry around, and procure information. The discovery that cognitive needs, and usage for information searching, are the most important need and usage aspects, clarify the social media usage pattern among Malaysians and verify the results of prior studies. Indeed, social media represents the most popular platform for searching and sharing of information at a time when people are being confronted by a crisis (Aisha et al., 2015; Ismail et al., 2020; Liu et al., 2015; Wang, 2021).

\section{CONCLUSION}

In conclusion, the three main objectives in this study of social media usage among audiences in Malaysia have successfully identified cognitive need, usage to search for information, and gratifications due to convenience, as the three variables that most greatly influenced social media usage when facing the Covid-19 pandemic in Malaysia. Though, it cannot be denied that technology determination also influenced uses and gratifications among the audiences in this country. The uniqueness of social media, coupled with the smartphone, gives it distinct advantages over other media forms. The audiences had a multitude of information options at their disposal that could bring numerous uses and forms of gratifications. Based on the use and gratification theory, it was observed that audiences connected their social media needs, uses and gratification aspects with the various social media channels that were deemed appropriate. Therefore, this situation created a variety of different usage patterns that were commensurate with their individual social media needs, uses and gratifications.

Funding: This study received no specific financial support.

Competing Interests: The authors declare that they have no competing interests.

Acknowledgement: All authors contributed equally to the conception and design of the study. 


\section{REFERENCES}

Aisha, T. S., Wok, S., Manaf, A. M. A., \& Ismail, R. (2015). Exploring the use of social media during the 2014 flood in Malaysia. Procedia-Social and Behavioral Sciences, 211, 931-937.Available at: https://doi.org/10.1016/j.sbspro.2015.11.123.

Akanda, A., \& Haque, M. A. (2013). Newspaper reading habits of university graduate students in Bangladesh: A case study. International Journal of Research in Applied, Natural and Social Sciences (IMPACT: IJRANSS), I(3), 1-8.

Akmar, H. G., \& Siti, Z. O. (2015). What kind of information needed by the youth. Journal of Media Critiques, 1(4), 2333.Available at: https://doi.org/10.17349/jmc115102.

Alhabash, S., \& Ma, M. (2017). A tale of four platforms: Motivations and uses of Facebook, Twitter, Instagram, and Snapchat among college students? Social Media+ Society, 3(1), 2056305117691544.Available at: https://doi.org/10.1177/2056305117691544.

Ambika, M., \& Samy, K. U. (2018). Newspaper reading habits among postgraduate students of Periyar University, Tamil Nadu. Journal of Advancements in Library Sciences, 5(3), 15-20.

Apuke, O. D., \& Omar, B. (2021). Fake news and COVID-19: Modelling the predictors of fake news sharing among social media users. Telematics and Informatics, 56, 101475.Available at: https://doi.org/10.1016/j.tele.2020.101475.

Cortese, J., \& Rubin, A. M. (2010). Uses and gratifications of television home shopping. Atlantic Journal of Communication, 18(2), 89-109.Available at: https://doi.org/10.1080/15456870903554924.

Foregger, S. (2009). The uses and gratifications of Facebook.com. Paper presented at the Annual Meeting of the NCA 95th Annual Convention, Chicago Hilton \& Towers, Chicago.

Ismail, S., Ariffin, H. S., \& Abdullah, Z. H. (2020). Social Media during a pandemic. Retrieved from https://oarep.usim.edu.my/jspui/bitstream/123456789/6805/1/MEDIA\%20SOSIAL\%20SEMASA\%2OPANDEMIK. pdf.

Jafar, A., George, F., Meri, A., Chong, V. H., Mapa, M. T., Sakke, N., \& Baco, Z. (202 1). Effectiveness of the national COVID-19 immunization program in East Malaysia. Malaysian Journal of Social Sciences and Humanities (MJSSH), 6(7), 1-11.

Katz, E., Gurevitch, M., \& Haas, H. (1973). On the use of the mass media for important things. American Sociological Revierw, 38(2), 164.Available at: https://doi.org/10.2307/2094393.

Kaur, S. (2020). The coronavirus pandemic in Malaysia: A commentary. Psychological Trauma: Theory, Research, Practice, and Policy, 12(5), 482-484.Available at: https://doi.org/10.1037/tra0000897.

Kircaburun, K., Alhabash, S., Tosuntaş, Ş. B., \& Griffiths, M. D. (2020). Uses and gratifications of problematic social media use among university students: A simultaneous examination of the Big Five of personality traits, social media platforms, and social media use motives. International Journal of Mental Health and Addiction, 18(3), 525-547.Available at: https://doi.org/10.1007/s11469-018-9940-6.

Ku, Y.-C., Chu, T.-H., \& Tseng, C.-H. (2013). Gratifications for using CMC technologies: A comparison among SNS, IM, and email. Computers in Human Behavior, 29(1), 226-234.Available at: https://doi.org/10.1016/j.chb.2012.08.009.

Lachlan, K. A., Hutter, E., Gilbert, C., \& Spence, P. R. (2021). From what I've heard, this is bad: An examination of Americans' source preferences and information seeking during the COVID-19 pandemic. Progress in Disaster Science, 9, 100145.Available at: https://doi.org/10.1016/j.pdisas.2021.100145.

Lee, K. T., Meri, A., , Nayan, L. M., \& Othman, S. S. (2016). Uses and gratifications news portal among youth in Malaysia. Malaysian Journal of Communication, 32(2), 790-816.Available at: https://doi.org/10.17576/jkmjc-2016-3202-38.

Lin, Y.-H., Hsu, C.-L., Chen, M.-F., \& Fang, C.-H. (2017). New gratifications for social word-of-mouth spread via mobile SNSs: Uses and gratifications approach with a perspective of media technology. Telematics and Informatics, 34(4), 382397.Available at: https://doi.org/10.1016/j.tele.2016.08.019.

Liu, B. F., Fraustino, J. D., \& Jin, Y. (2015). How disaster information form, source, type, and prior disaster exposure affect public outcomes: Jumping on the social media bandwagon? Journal of Applied Communication Research, 43(1), 4465.Available at: https://doi.org/10.1080/00909882.2014.982685. 
López, C., Hartmann, P., \& Apaolaza, V. (2019). Gratifications on social networking sites: The role of secondary school students' individual differences in loneliness. Journal of Educational Computing Research, 57(1), 58-82.Available at: https://doi.org/10.1177/0735633117743917.

Malaysian Communications and Multimedia Commission. (2020). Internet users survey 2020. Retrieved from https://www.mcmc.gov.my/skmmgovmy/media/General/pdf/IUS-2020-Report.pdf

Mathew, J., Ogedede, P. M., \& Adenji, S. B. (2013). Online newspaper readership in the North Eastern Nigeria. Asian Journal of Social Sciences and Humanities, 2(2), 239-238.

Maxwel, E. E. (2012). Motivation to tweet: A uses and gratification perspective of Twitter use during a natural disaster. Master Thesis, University of Alabama United States.

Meri, A., \& Lee, K. T. (2021). News portal usage among teenagers in Sabah. Borneo Journal of Communication, 9(6), $16-27$.

Meri, A., Lee, K. T., Yusoff, S. M., \& Modili, C. (2020). Needs, uses and gratifications news portal among Kadazandusun teenegers in Sabah. Kinabalu Journal, 26(1), 41-58.

Michailina, S., Andreas, M., \& Christos, P. (2015). Understanding online news sites and social media. International Journal of Strategic Innovative Marketing, 3(2015), 1-13.

Nayan, L. M., Devarajoo, A. R., Othman, S. S., Lee, K. T., \& Hasan, N. N. N. (2016). Online newpaper uses among university students. Journal of Human Capital Development, 9(1), 119-130.

Rubin, A. M. (2009). Uses and gratifications perspective of media effects. In J. Bryant \& M.B. Oliver (Eds.), Media effects: Advances in theory and research (3rd ed., pp. 165-184). New York: Routledge.

Ruggiero, T. E. (2000). Uses and gratifications theory in the 21 st century. Mass Communication $\&$ Society, 3(1), 3-37.Available at: https://doi.org/10.1207/s15327825mcs0301_02.

Shim, H., You, K. H., Lee, J. K., \& Go, E. (2015). Why do people access news with mobile devices? Exploring the role of suitability perception and motives on mobile news use. Telematics and Informatics, 32(1), 108-117.Available at: https://doi.org/10.1016/j.tele.2014.05.002.

Wang, X. (2021). The motivations and uses of mainstreamand social media during the COVID-19 pandemic in China: A structural equation modeling approach. Computers in Human Behavior Reports, 4, 100098.Available at: https://doi.org/10.1016/j.chbr.2021.100098.

Wimmer, R. D., \& Diminick, J. R. (1994). Mass media research: An introduction. Belmont, CA: Wadsworth.

World Health Organization. (2020). Covid-19 situation overview in Malaysia. Retrieved from https://www.who.int/malaysia/internal-publications-detail/covid-19-in-malaysia-situation-report-01.

Wu, J.-H., Wang, S.-C., \& Tsai, H.-H. (2010). Falling in love with online games: The uses and gratifications perspective. Computers in Human Behavior, 26(6), 1862-1871.Available at: https://doi.org/10.1016/j.chb.2010.07.033.

Yassin, M. (2020). Special message from the Prime Minister COVID-19 (Special Message by Prime Minister on Covid-19). Retrieved from https://www.kln.gov.my/web/chn_xian/announcements//asset_publisher/LRar911Tfz8G/blog/perutusan-khas-yab-perdana-menteri-mengenai-covid-19-pada-18-mac-2020.

Zhu, N., Zhang, D., Wang, W., Li, X., Yang, B., Song, J., \& Lu, R. (2020). A novel coronavirus from patients with Pneumonia in China, 2019. The New England Journal of Medicine, 382(8), 727-733.

Views and opinions expressed in this article are the views and opinions of the author(s), Humanities and Social Sciences Letters shall not be responsible or answerable for any loss, damage or liability etc. caused in relation to/arising out of the use of the content. 